УДК 811.161.1'42

ББК 81.2Рус-5

DOI: https://doi.org/10.17308/lic.2020.3/2942

\title{
КВАНТИФИКАЦИЯ МЕСТОИМЕНИЙ \\ В ЖАНРЕ АГИТАЦИОННОЙ РЕЧИ
}

\author{
Р. Д. Урунова \\ Казанский федеральный университет \\ QUANTIFICATION OF PRONOUNS
IN THE GENRE OF CAMPAIGN SPEECH \\ R. D. Urunova \\ Kazan Federal University
}

\begin{abstract}
Аннотация: целью данной статьи является описание квантификации в агитационной речи и принциов применения кванторных местоимений, а также местоимений, которые подверглись квантификации, для конкретных жанровых задач в контексте. В статье уделяется внимание функииональному синкретизму местоимений, результатом которого является особый тип квантифицированных местоимений, широко применяемых в агитационных речах. Для корректности описания приемов использования кванторных и квантифииированных местоимений в исследовании был применен комплексный контекстуальный, функциональный и статистический анализ. Кроме этого, в методологическом аспекте рассматривается эпистимологическая категория «возможный мир» как имеющая высокую иченность для процедуры описания кванторных и квантифицированных местоимений в жанре агитационной речи. Материалом для исследования послужсил фрагменты агитационных речей известных политиков, которые были написаны в разные периоды и по разному поводу. В статье выдвигается и отстаивается положение, что оратор, выражающий себя местоимениями, задает разные по качеству и степени конкретности типь отражения мира в контексте речи. В этой связи выдвигается предположение, что кванторные и квантифицированные местоимения позволяют выступающему обобщить представление о предмете речи, и тем самым добиться его отвлеченности, что, в свою очередь, позволяет символизировать представление о мире. Символический мир часто становится предметом обсуждения в агитационных речах как положение дел, к которому оратор призывает. Автор делает вывод, что использование кванторных и квантифииированных местоимений с обобщенной семантикой для описания перспективы - распространенный и эффективный прием в агитационных речах. Материал статьи может быть использован на занятиях по риторике, функииональной грамматике и в исследовательской практике.
\end{abstract}

Ключевые слова: квантификация, агитационная речь, кванторные местоимения, квантифицированные местоимения, дейктические местоимения, функииональный синкретизм.

\begin{abstract}
: the purpose of this article is to describe quantification in agitation speech and the principles of applying quantifier pronouns, as well as pronouns that have undergone quantification, for specific genre problems in the context. The article focuses on functional syncretism of pronouns, which results in a specific type of quantified pronouns that are widely used in campaign speeches. To correctly describe the methods of using quantifier and quantified pronouns, the study uses a comprehensive contextual, functional, and statistical analysis. In addition, the epistemological category "possible world" is considered in the methodological aspect as having a high value for the procedure of describing quantified and quantified pronouns in the genre of agitation speech. The material for the study was fragments of campaign speeches of famous politicians, which were written in different periods and on different occasions. The article puts forward and defends the position that a speaker who expresses himself with pronouns sets different types of reflection of the world in the context of speech in terms of quality and degree
\end{abstract}

(C) Урунова Р. Д., 2020

Контент доступен под лицензией Creative Commons Attribution 4.0 License.

The content is available under Creative Commons Attribution 4.0 License. 
of concreteness. In this regard, it is suggested that quantifiable and quantified pronouns allow the speaker to generalize the idea of the subject of speech, and thus achieve its abstraction, which, in turn, allows to symbolize the idea of the world. The symbolic world is often discussed in campaign speeches as a state of Affairs that the speaker calls for. The author concludes that the use of quantized and quantified pronouns with generalized semantics to describe the perspective is a common and effective technique in campaign speeches. The material of the article can be used in classes on rhetoric, functional grammar, and in research practice.

Key words: quantification, campaigning speech, quantifier pronouns, quantified pronouns, deictic pronouns, functional syncretism.

\section{Введение}

Владение словом всегда высоко ценилось в обществе, а в политических сферах оно является непременным условием успешности политика, поскольку принимается за свидетельство его способностей. В современных условиях красноречие стало еще более ценным качеством для политических деятелей, поскольку благодаря техническим возможностям кардинально увеличился масштаб аудитории. Ученые, занимающиеся риторическими исследованиями, выделяют разные виды красноречия в зависимости от сферы и ситуации использования: политическое, академическое, педагогическое, судебное, военное, дипломатическое и др. [1-3]. Каждый вид красноречия используется ораторами в речах определенных жанров. Е. Н. Зарецкая считает, что ораторская речь является «однократным речевым актом», в процессе которого необходимо удержать интерес аудитории к предмету речи, и соответственно «завоевание внимания аудитории и есть реализованное ораторское мастерство» [1, с. 262]. По этой причине жанры ораторских речей обусловливаются целым рядом факторов, часть которых являются внешними для языкового качества речи, но от которых зависит успешность выступления, например, коммуникативная ситуация, качественный и количественный состав аудитории, качество и степень внимания аудитории, внешность оратора и тембр его голоса [Там же]. В риторике на сегодняшний день разработано довольно большое количество классификаций жанров ораторских речей по разным языковым и неязыковым признакам, но всеми признается, что самой продуктивной является типология по целевой установке. Но и по целевой установке разные ученые выделяют разные типы речей. Так, Е. Н. Зарецкая делит речи на авторитарные, демократические и либеральные [1, с. 104]. А П. Л. Сопер в связи с тем, что «общая цель заключается в том, чтобы развлечь, информировать, воодушевить, призвать к действию», делит все речи на развлекательные, информационные и агитационные [2, c. 41].

Как бы ни различались подходы к выделению типов, агитационные речи представлены во всех классификациях. Хотя агитационный жанр в разных классификациях рассматривается в разных аспектах (например, Е. Н. Зарецкая по способу достижения цели, а П. Л. Сопер по собственно цели) [1, с 104; 2 , c. 41], все ученые признают, что главным критерием агитационных речей является побуждение к действию. Эта цель, по мнению М. М. Бахтина, и определяет одно из самых важных требований к жанру: агитационная речь должна быть адресованной, адресат должен быть осведомленным о предмете речи и должен с сочувствием воспринимать речь [3, с. 161]. Агитационной речи свойственны черты, характерные и для других речей: она должна содержать необходимые фактические данные, активизировать психическую восприимчивость, приводить к согласию. Кроме этого, ей характерно особое функциональное свойство: она должна заставить слушателей почувствовать потребность сделать то, о чем просит ее оратор. Для выполнения этих требований оратор должен оказывать воздействие на свою аудиторию, используя самые разные приемы, в том числе и определенные языковые средства, в состав которых входят местоимения. Статистические наблюдения показывают, что довольно часто употребляемым риторическим средством агитационного жанра являются кванторные местоимения и местоимения других разрядов, подвергаемые квантификации. В данной статье некванторные местоимения, которые подвергаются квантификации, определяются как квантифицированные. В жанре агитационной речи кванторные и квантифицированные местоимения можно рассматривать как одно из продуктивных средств воздействия на аудиторию в некоторых ситуациях, поскольку в отличие от других элементов, таких как фигуры речи и эмоционально окрашенные лексемы, они остаются обычными нейтральными словами, не привлекающими внимания, и в силу этого воздействуют на слушателей имплицитно и поэтому эффективно.

Местоимения занимают особое место среди других классов слов, поскольку у них функциональная ценность коммуникативных свойств выше, чем значимость грамматических свойств. Иными словами, функции местоимения в коммуникативном акте доминируют над функциями в синтаксической конструкции. Вероятно, поэтому местоимения, относящиеся к разным разрядам, могут кардинально отличаться друг от друга своими грамматическими каче- 
ствами, что практически не встречается у других частей речи. Грамматические качества отвечают за сочетаемость слов в контексте, а коммуникативные позволяют местоимениям в устном формате организовывать коммуникативный акт, а в письменном обеспечивать соотнесенность разных объектов и частей текста. Двухуровневая функциональная природа стала причиной того, что переходность, или синкретизм, является одним из свойств, характерных для всех местоименных слов, поэтому одно местоимение в разных контекстах может выполнять функции разных разрядов [4; 5]. Для настоящей статьи принципиально важно, что в публичных речах некоторые некванторные местоимения часто выполняют функцию квантификации, и это свидетельствует о том, что данная функция имеет определенную ценность для жанров этого типа.

По семантическим, логическим и функциональным качествам местоимения делятся на три разряда: дейктические, анафорические и кванторные. Местоимения каждого разряда в агитационных речах выполняют свою особую функцию. Дейктические местоимения обеспечивают организацию акта коммуникации оратора с аудиторией, актуализируя его структуру. Кроме этого, они осуществляют пространственный дейксис, который заключается в координации содержания речи в пространстве. Анафорические местоимения разгружают контекст речи от повторения одних и тех же единиц. Кроме этого, они служат средством соотнесения между собой субъектов и объектов речи, а в тексте еще и смысловых частей. Кванторные местоимения осуществляют квантификацию, т. е. информируют о количественной характеристике качественных признаков. Кроме этого, они актуализируют соотношения элементов и частей внутренней структуры контекста. В публичной речи местоимения-кванторы используются специфически даже по сравнению с другими местоимениями, например, они только в особых случаях сопровождаются коррелятами, тогда как остальные местоимения, как правило, используются с антецедентами или с антиципентами [6, с. 110].

Обычно основной сферой употребления собственно кванторных местоимений являются тексты с обобщенным смыслом (притчи, пословицы, гимны и пр.) [6, с. 87-92], но исследования некоторых ученых [6-8] и наблюдения показывают, что этот вид местоимений также часто употребляется в публицистических жанрах с повышенной функцией воздействия, например в ораторских речах с социально-политическим красноречием, направленных на решение социальных, экономических и политических вопросов. Такая речь, как правило, содержит определение задач и целей, а также практические рекомендации к действию для аудитории. Оратор своей речью должен убедить своего слушателя принять его позицию в какой-либо ситуации и как следствие быть готовым к определенным действиям. Это невозможно осуществить без чувства сопереживания и общности между выступающим и его слушателями. Конечно, основная нагрузка воздействия для достижения этой цели зависит от одаренности выступающего перед аудиторией, но, безусловно, большую роль в этом играют местоимения, особенно кванторные либо выполняющие функцию квантификации. Наблюдения показывают, что использование таких местоимений является одним из наиболее часто применяемых в социально-политических речах ораторских приемов, и этот факт делает кванторные и квантифицированные местоимения перспективным объектом для исследования.

\section{Материалы и методы исследования}

Анализ ряда текстов агитационных речей, произнесенных политиками по разным поводам (президентские выборы, обращение к народу в связи с экстремальной ситуацией, обращение к собранию, выборы в правительство, дискуссия и др.), показал, что кванторные местоимения, в отличие от дейктических и анафорических, репрезентируют реалию через ее вхождение в определенный класс. При этом неважными являются отличительные уникальные признаки этой реалии: она значима только как элемент определенного множества: И сегодня я просто обязан сказать слова благодарности всем, кто в этой трудной ситуации отстоял демократические завоевания народа; Надо также признать, что некоторые ближайшие соседи России и страны Восточной Европь проводили преобразования и быстрее, и решительнее (Путин). Эта особенность кванторных местоимений обусловлена их логической природой. Фактически они функционируют в тексте как актуализаторы логических кванторов, отсюда и их название. «Кванторы (от лат. quantum - сколько) - это принятое в исчислении предикатов математической логики название логических операторов, которые описывают соотношения внутренней структуры высказывания, т. е. отношения между субъектом и предикатом, и несут информацию о количественной характеристике логического выражения, перед которым они поставлены» [9, с. 212]. В логике различают два вида кванторов:

1) квантор общности используется в общих суждениях типа: «Для всех $x$ имеет место $A(x)$ » $[9$, c. 212]. В обычной речи логический смысл квантора общности актуализируется местоимениями всякий, каждый, все и др.; 
2) квантор существования используется в частных суждениях типа: «Существует $x$, для которого выполняется $A(x) »[9$, с. 212]. В обычной речи логический смысл квантора существования актуализируется местоимениями один, несколько, некий и др.

Таким образом, кванторные местоимения - это слова, которые содержат в своем значении указание на всеобщность, неопределенность, частотность, универсальность, частность и пр. Они либо обобщают высказывания, либо дают количественную характеристику качества каких-либо предметов и явлений.

Благодаря логической природе особенности использования кванторных местоимений в жанре агитационной речи хорошо поддаются исследованию эпистемологическими методами, в частности при помощи понятия «возможный мир» в интерпретации финского ученого Я. Хинтикки и некоторых российских ученых [10-12]. «“Возможный мир” можно интепретировать либо как возможное положение дел, либо как возможное направление развития событий (различие этих интерпретаций не существенно)» [10, c. 38]. Я. Хинтикка отмечает: «Каждый, кто когда-либо думал, скажем, о вероятности различных возможностей относительно завтрашней погоды, тем самым рассматривал и несколько “возможных положений дел”. Каждый, кто когда-либо обдумывал то, что он воспринимает в данной ситуации, тем самым неявно классифицировал возможное положение дел на совместимые с содержанием его восприятия и не совместимые с ним, так как именно это и означает описание его восприятий» [10, с. 39]. Анализируя концепцию Я. Хинтикки, российский ученый Е. Д. Смирнова уточнила, что для него чрезвычайно важно, что «границы возможных миров задаются языком, его возможностями» [12, с. 48].

Возможный мир как научная категория в эпистемологических исследованиях рассматривается в виде модельных множеств. По мнению Е. Д. Смирновой, из-за того что границы возможных миров задаются возможностями языка, модельные множества подобны описаниям состояний посредством предложений языка. Но в отличие от описаний состояний, описания модельных множеств включают не только атомарные предложения, но и сложные высказывания, расширяя тем самым описания [12]. Однако важно учесть, что Я. Хинтикка склонен рассматривать модельные множества не как описания миров, а скорее как задающие виды описаний. Принципиально важно уяснить следующее: речь идет не о возможных положениях дел где-то и как-то реализуемых или вовсе нереализуемых - речь идет о построении «картин миров» [12, c. 46]. На базе модельных множеств определяются основные семантические понятия контента, и в данном случае речь идет о языковой репрезентации возможного мира, средствах его задания в языке, а для данной статьи о кванторных и квантифицированных местоимениях как средстве задания возможного мира в агитационной речи.

Модельные множества состоят из личных модальностей. «Личные модальности» - это «пропозициональные установки», на которых строится какой-либо конкретный возможный мир. При операторной трактовке «личные модальности» устанавливаются в каждом конкретном случае заново по отношению к некоторому субъекту. Фактически каждый «заданный возможный мир» зависит от качества субъекта (т. е. автора контекста, в нашем случае агитационной речи), так как именно он определяет основные категории этого мира. В этом свете проппозициональные установки являются фундаментом, на котором строится возможный мир, поэтому они позволяют осуществить его верификацию [12, с. 48] или создать видимость верификации, и эта особенность часто используется авторами агитационных речей для собственной убедительности перед аудиторией.

Анализ личных модальностей в процессе исследования агитационных текстов дает возможности описать функциональные и стилистические особенности местоимений, которые часто актуализируют кванторы возможных миров, характеризующихся с помощью некоторого числа условий, по существу представляющих собой переформулированные условия истинности, что используется ораторами как прием убеждения аудитории. Анализ модельных множеств из разных контекстов показал:

1) если субъект выражен обычным знаменательным словом или некванторным местоимением (например, дейктическим), то он задает основные параметры возможного мира [8, с. 126]. Такой субъект является ориентиром, определителем предметной области возможного мира, и одновременно его ча-

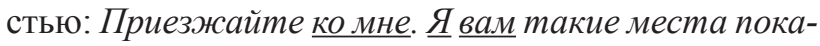

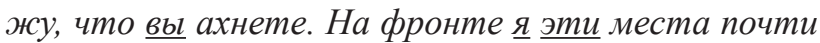
каждую ночь видел во сне (Паустовский); Дискуссию на эту тему я считаю малоэффективной» (Медведев);

2) если же субъект выражен кванторным местоимением, то он не может репрезентировать конкретную предметную область, а только абстрактную [8, с. 126]: У людей уже складывается понимание, что размер пенсии будет зависеть от их собственного трудового вклада, и что каждый гражданин имеет возможность управлять своими пенсионными накоплениями (Путин); Борьбу с коррупщией должно вести государство, так во всем мире. (Медведев).

Конкретность или абстрактность кванторного местоимения как субъекта некоторого возможного мира определяет конкретность или абстрактность самого возможного мира. Таким образом, за квантор- 
ными и квантифицированными местоимениями всегда стоит один из допустимых вариантов возможного мира, субъектом которого может быть любое лицо, отвечающее условиям, из которых складывается модельное множество. Происходит обратная мотивация: если конкретный субъект является определителем пропозициональных установок возможного мира, то с кванторным субъектом, напротив, пропозициональные установки возможного мира являются условиями, определяющими сам субъект. Качества, которые не входят в условия возможного мира, являются незначимыми для кванторного субъекта. В этом аспекте становится понятным, почему в агитационных речах политиков так часто осуществляется квантификация и используются кванторные местоимения, которые, выражая субъекта речи, имплицитно репрезентируют и некий абстрактный символический возможный мир, который является для субъекта характеризующим.

\section{Результаты исследования}

Изучение кванторных местоимений в эпистимологическом аспекте позволило выявить, что в семантическом плане они соотносятся с целым классом лиц, объектов или понятий, поэтому в отличие от знаменательных слов и местоимений других разрядов они часто осуществляют деконкретизацию содержания контекста. Контекстуальный анализ фактического материала показал, что в этом плане они противопоставляются дейктическим местоимениям, функция которых, напротив, персонализировать и тем самым конкретизировать контексты, что они осуществляют с большой точностью. Функциональный анализ, в свою очередь, показал, что в жанре агитационной речи широко проявляется способность местоимений к функциональному синкретизму, и часто именно дейктические местоимения подвергаются квантификации. Квантифицированные дейктические местоимения начинают деконкретизировать предмет речи, при этом, однако, продолжая выполнять свою основную коммуникативную функцию. В процессе деконкретизации происходит соотнесение объекта, выраженного кванторным или квантифицированным местоимением, с классом понятий. При этом индивидуальность и персональность объекта для контекста принципиально не важны, а иногда, особенно в ораторских речах, и нежелательны: 1) Я думаю, что $\underline{\mathrm{\mu u}}$ одно миролюбивое государство не может отказаться от мирного соглашения с соседней державой, если во главе этой державы стоят даже такие изверги и людоеды, как Гитлер и Риббентроп (Сталин). 2) Отчасти дурную шутку сыграла с нами и глобализация, к которой мы так все стремились (Медведев). 3) Уверен, что действующему главе государства не следует заниматься собственной рекламой-надо было делать это в течение четырех лет: митинговать, сочинять всякие красивые сказки, красивье, но далекие от нашей реальной жизни (Путин). 4) И $\underline{\text { ни }}$ один человек никогда не выйдет сюда, потому что здесь слово дает только председатель собрания. И никто не будет бегать у микрофонов и говорить, с какого он округа (Жириновский).

Квантификация некоторых дейктических местоимений требует особого внимания, поскольку по частоте встречаемости это явление можно считать характерным для жанра агитационной речи. Так, местоимения $\mathbf{M b l}, \mathbf{н а ш u , ~} \mathbf{b b l}$, ваши в агитационных речах особенно часто подвергаются квантификации, при этом они одновременно продолжают выполнять и свою основную коммуникативную функцию. Местоимения $\mathbf{m b l}$, наши в кванторной функции довольно часто используются для выражения общности всех людей, в том числе и говорящего, в какой-либо ситуации: $\underline{M b l}$ (т. е. все, или каждый человек) почти всегда извиняем то, что понимаем (Лермонтов). Благодаря функциональному синкретизму, эти местоимения в агитационном контексте используются как средство достижения эффекта общности для того, чтобы вызвать у аудитории чувство солидарности с оратором: $\mathrm{Mbl}$ должны немедленно перестроить всю нашу работу на военный лад, все подчинив интересам фронта и задачам организаџии разгрома врага; Все наши силь - на поддержку нашей герочческой Красной Армии, нашего славного Красного Флота! Все сильг народа - на разгром врага! Вперед, за нашу победу! (Сталин).

Местоимения 2-го лица $b b l$, ваши и даже $m b l$ также могут подвергаться квантификации с целью достижения эффекта общности, но при их кванторном использовании они одновременно акцентируют личностную самостоятельность адресата речи. Наглядным примером этой особенности является агитационный текст в известном плакате - Tbl записался добровольцем? - созданном художником Дмитрием Моором во время Гражданской войны в России. В нем местоимение $m b l$ употреблено в значении квантора общности, но с дополнительной персонализированной коннотацией, т. е. «ты тоже должен», «ты, как и все, должен», «ты как один из всех». Данный пример хорошо иллюстрирует функциональный синкретизм местоимения mbl. С одной стороны, mbl в данном контексте - это адресат (дейктическая функция), с другой стороны - это обобщающее слово (функция квантификации). Следует отметить, что при квантификации местоимений 2-го лица сема адресата, являющаяся персонализированной коннотацией, всегда остается активной в семантической структуре. Это хорошо иллюстрируют два примера из предвыборных речей Г. Зюганова и В. Путина, которые имеют прак- 
тически идентичное содержание, но из-за употребления разных квантифицированых местоимений различаются степенью квантификации: Каждый из вас будет обеспечен достойным жильем (Зюганов); Как я уже говорил, наша важнейшая задача - решить жилищную проблему (Путин). Заявление Путина является более абстрактным, несмотря на употребление личного $я$, тогда как местоименная конструкция каждый из вас в речи Зюганова, будучи квантором общности, усиливает экспрессию всей фразы своей адресной точностью.

Следует заметить, что дейктическое местоимение $я$ (в отличие от $m b l$ ) не поддается квантификации, оно всегда остается персонализированным самовыражением говорящего. Статистический анализ показывает, что это местоимение сравнительно редко употребляется ораторами в агитационных речах, очевидно, из-за того, что у него нет способности к квантификации, поскольку за ним всегда открывается персонализированный возможный мир. Все же некоторые политики используют это местоимение для самовыражения, например, депутат Государственной Думы от коммунистической партии Г. А. Зюганов в своих речах: Я хочу, чтобы каждый понял, за что травили губернатора Иркутской области Сергея Левченко; Я понимаю, что журналисты подневольные люди, но какой надо быть политической сволочью, чтобь отдать приказ вести эту грязную работу!; Я обращзаюсь к журналистам: вы еще не устали от этой подлости?; И я хочу, чтобы в Кремле усльшили: Ленин был гением! Президент Республики Беларусь А. Г. Лукашенко также часто использует в своих речах это местоимение для самовыражения: Я не подписал Таможенный кодекс (ЕврАзЭС), потому что многое, что должно было быть, не работает. Более того, я поручил отозвать основных наших специалистов из таможенных органов (ЕврАзЭС). Контекстуальный анализ приведенных фрагментов показал, что в их контексте было уместно употребление официального квантифицированного $\mathrm{Mbl}$, поскольку оба политика выступают от лица своих партий, но они отдали предпочтение личному я. Контекстуально-статистическое изучение агитационных речей этих политиков показывает, что репрезентация местоимением я является особенностью их ораторского стиля. Другие политики тоже используют это местоимение, но только в тех случаях, когда речь идет о какой-то сугубо персональной ситуации: Мне часто задают вопрос: буду ли я проводить избирательную кампанию, и если буду - то как (Путин); Я лично говорил об этом во время встреч тогда ещце всем нужной «восьмерки» (Медведев); У меня нет иллюзий по поводу роли моей скромной персонь в истории российского парламентаризма (Миронов); Я ухожу, но я не оставляю вам преемни- ка, потому что наступило время прямой демократии (Жириновский).

Местоимения $\mathrm{Mbl}$ и $\mathrm{bbl} / \mathrm{mbl}$ употребляются для квантификации в агитационных речах чаще, чем другие некванторные местоимения. Причиной этого является их способность ненавязчиво вызывать чувство общности участников коммуникации, что охотно используется для агитации как один из самых эффективных ораторских приемов воздействия на аудиторию. Так, в знаменитой Геттисбергской речи Авраама Линкольна, сравнительно небольшой по объему, из 242 слов 48 местоимений, из которых 26 кванторные и из них 15 кватифицированных местоимений - $\mathbf{m b l}$, наши. Эти местоимения в речи Линкольна несут большую экспрессивную нагрузку, вызывая у каждого адресата ощущение общности с оратором и одновременно со всем американским народом.

Изучение предвыборного выступления Владимира Путина перед доверенными лицами 12 февраля 2004 г. показало: в контексте анализа имеющегося состояния дел он часто использует кванторное местоимение все (весь, вся, всё), но когда он говорит о перспективах развития страны, использует квантифицированные местоимения $\mathbf{M b}$, наши. Следующие примеры являются характерными для употребления этим политиком приведенных местоимений: Начиная с 2000 г. достигнута положительная динамика всех основных сочиальных показателей; Хотел бы здесь подчеркнуть: несмотря на весь масштаб перемен, мы лишь создали плацдарм для решительного поворота в экономическом развитии страны, поворота, ведущего к качеству жизни, сопоставимому с развитылм странами, и уже через это - к такому авторитету и к такому влиянию России, которые будут достойны и нашей тысячелетней истории, и наших интеллектуальных ресурсов, и наших возможностей для полноченного участия в мировом разделении труда.

Сопоставление особенностей употребления кванторных и квантифицированных местоимений в текстах разных жанров [6] показывает, что они выделяются в контексте своей принадлежностью к книжному стилю, и их значимость в этом отношении трудно переоценить особенно в притчевых и пословичных текстах. В жанре агитационной речи кванторные, и особенно квантифицированные местоимения, в стилистическом плане не так заметны, но тем не менее они несут большую функциональную нагрузку, выступая как средство воздействия на аудиторию, что является одной из главных задач ораторских речей. Во всех приведенных выше примерах из речей политиков участники коммуникативной ситуации не конкретизируются, а лишь намечаются благодаря использованию местоимений с обобщающей семан- 
тикой, и таким образом агитационному контенту придается абстрактный и одновременно символический смысл. Большая часть кванторных и квантифицированных местоимений используется в речи осознанно, мотивированно, для достижения цели, важной для сообщения, в рамках которого они употребляются.

\section{Заключение}

Контекстуальный анализ особенностей употребления каждого типа местоимений показал, что квантификация в агитационных речах осуществляется двумя способами. Во-первых, при помощи собственно кванторных местоимений, и во-вторых, путем квантификации дейктических местоимений. В связи с этим можно сделать вывод, что квантификация выполняет в агитационной речи, по крайней мере, две важные функции. Первую функцию выполняют собственно кванторные местоимения со значением общности и существования, которые используются для того, чтобы придать предмету речи категориальный масштаб. Вторую функцию выполняют квантифицированные местоимения. Они не только обобщают предмет речи, но и вызывают у слушателей чувство солидарности с оратором. В агитационной речи выступающий выполняет сразу две задачи: с одной стороны, он организует речевую коммуникацию, поскольку агитационная речь осуществляется устно непосредственно перед аудиторией, а с другой стороны, он создает воздействующий контент, который обязательно должен быть аналитическим или хотя бы иметь элементы аналитики. В этих условиях ораторы используют квантифицированные местоимения $\mathrm{Mbl}$, $m b l$, в $ы$ сразу в двух функциях одновременно: во-первых, для организации коммуникативного пространства, а во-вторых, для обобщения, чтобы вызывать у аудитории сочувствие и желание или даже потребность выполнить то, к чему он их призывает. Кроме этого, квантифицированные местоимения, употребленные выступающим для самовыражения, задают абстрактный возможный мир в содержании речи, как правило, являющийся идеальным, и этот мир воспринимается аудиторией как характеризующий оратора.

\section{ЛИТЕРАТУРА}

1. Зарецкая Е. Н. Риторика : теория и практика речевой коммуникации. М. : Дело, 2001. 480 с.

2. Сопер П. Л. Основы искусства речи. М. : Прогресс : Прогресс-академия, 1992. 415 с.

3. Бахтин М. М. Проблема речевых жанров // Бахтин М. М. Собр. соч. М. : Языки русской культуры, 1996. T. 5. C. 159-286.

4. Мигирин В. Н. Очерки по теории процессов переходности в русском языке. Бельцы, 1971. 199 с.
5. Сидоренко Е. Н. Очерки по теории местоимений современного русского языка. Киев ; Одесса : Лыбидь, 1990. $147 \mathrm{c}$.

6. Урунова Р. Д. Местоимения русского языка. Разноаспектное описание. Ульяновск : УлГУ, 2014. 175 с.

7. Казакова И. Н. Речевые структуры, репрезентирующие авторскую стратегическую модель в передаче «Наблюдатель» // Русский язык и литература в образовательном процессе. Саратов : МарК, 2016. С. 33-37.

8. Урунова Р. Д. К вопросу об особенностях кванторных местоимений // Известия ВГПУ. Филологические науки. 2019. № 6(139). С. 124-128.

9. Кондаков Н. И. Логический словарь. М. : Наука, $1971.655 \mathrm{c}$.

10. Хинтикка Я. Логико-эпистемологические исследования // Логика и методология науки. М. : Прогресс, $1980.448 \mathrm{c}$.

11. Хинтикка Я. Виды модальностей // Семантика модальных и интенсиональных логик. М. : Прогресс, $1981.424 \mathrm{c}$.

12. Смирнова Е. Д. Возможные миры и понятие «картин мира»// Вопросы философии. 2017. № 1. C. $39-50$.

\section{ИСТОЧНИК}

Примеры ораторской речи в различных сферах жизни человека. URL: https://vseorechi.ru/ritorika/orator/ oratorskaya-rech-primery.html

\section{REFERENCES}

1. Zaretskaya E. N. Ritorika: Teoriya i praktika rechevoj kommunikacii [Rhetoric: Theory and practice of speech communication]. M.: Delo, 2001. 480 p.

2. Soper P. L. Osnovy 'iskusstva rechi [Basics of the art of speech]. Moscow: Progress: Progress-akademiya, 1992. $415 \mathrm{p}$.

3. Baxtin M. M. Problema rechevy'x zhanrov [The problem of speech genres]. In Collected works: Moscow: Yazy`ki russkoj kul`tury`, 1996. T. 5. Pp. 159-286.

4. Migirin V. N. Ocherki po teorii processov perexodnosti v russkom jazy ke [Essays on the theory of transitivity processes in Russian]. Bel'cy, 1971. 199 p.

5. Sidorenko E. N. Ocherki po teorii mestoimenij sovremennogo russkogo jazy $k a$ [Essays on the theory of pronouns in modern Russian]. Kiev; Odessa: Ly'bid’, 1990. $147 \mathrm{p}$.

6. Urunova R. D. Mestoimeniya russkogo jazy `ka. Raznoaspektnoe opisanie [Pronouns of the Russian language. Multi-aspect description]. Ul yanovsk: UlGU, 2014. 175 p.

7. Kazakova I. N. Rechevy`e struktury`, reprezentiruyushhie avtorskuyu strategicheskuyu model' $\mathrm{v}$ peredache «Nablyudatel '» [Speech structures that represent the author's strategic model in the program "Observer"]. In Russkij yazy $k$ i literatura $v$ obrazovatel nom processe [Russian language and literature in the educational process]. Saratov: ID «MarK», 2016. Pp. 33-37. 
8. Urunova R. D. K voprosu ob osobennostyax kvantorny'x mestoimenij [On the question of the features of quantifier pronouns]. In Izvestiya VGPU. Filologicheskie nauki [News of VSPU. Philological science]. 2019. No. 6(139). Pp. 124-128.

9. Kondakov N. I. Logicheskij slovar ' [Logical dictionary]. Moscow: Nauka, 1971. 655 p.

10. Hintikka Y. Logiko-e pistemologicheskie issledovaniya [Logical-epistemological research]. In Logika $i$ metodologiya nauki [Logic and methodology of science]. M.: Progress, 1980. 448 p.

11. Hintikka Y. Vidy` modal'nostej [Types of modalities]. In Semantika modal 'ny $x$ i intensional 'ny ’ $x$ logic

Казанский федеральный университет

Урунова Р. Д., доктор филологических наук, доиент кафедры гуманитарных дисииплин

E-mail: urunova-rd@yandex.ru

Поступила в редакцию 23 апреля 2020 г.

Принята к публикачии 15 июня 2020 г.

\section{Для цитирования:}

Урунова Р. Д. Квантификация местоимений в жанре агитационной речи // Вестник Воронежского государственного университета. Серия: Лингвистика и межкультурная коммуникация. 2020. № 3. C. 122-129. DOI: https://doi.org/10.17308/lic.2020.3/2942
[Semantics of modal and intensional logics]. M.: Progress, 1981. $424 \mathrm{p}$.

12. Smirnova E. D. Vozmozhny`e miry` i ponyatie «kartin mira» [Possible worlds and the concept of «world pictures»]. In Voprosy 'filosofii [Issues in philosophy]. 2017. No. 1. Pp. 39-50.

\section{SOURCE}

Primery'oratorskoj rechi $v$ razlichny'x sferax zhizni cheloveka [Examples of oratory in various areas of human life]. Available at: https://vseorechi.ru/ritorika/orator/ oratorskaya-rech-primery.html

Kazan Federal University

Urunova R. D., Doctor of Philology, Associate Professor of the Humanitarian Disciplines Department

E-mail: urunova-rd@yandex.ru

Received: 23 April 2020

Accepted: 15 June 2020

\section{For citation:}

Urunova R. D. Quantification of pronouns in the genre of campaign speech. Proceedings of Voronezh State University. Series: Linguistics and Intercultural Communication. 2020. No. 3. Pp. 122-129. DOI: https://doi.org/ 10.17308/lic.2020.3/2942 